\title{
An examination of inter-hemispheric conjugacy in a subauroral polarization stream
}

\author{
B. S. R. Kunduri, ${ }^{1}$ J. B. H. Baker, ${ }^{1}$ J. M. Ruohoniemi, ${ }^{1}$ L. B. N. Clausen, ${ }^{2}$ A. Grocott, ${ }^{3}$ \\ E. G. Thomas, ${ }^{1}$ M. P. Freeman, ${ }^{4}$ and E. R. Talaat ${ }^{5}$ \\ Received 2 April 2012; revised 9 July 2012; accepted 11 July 2012; published 28 August 2012.
}

[1] During geomagnetically disturbed conditions the midlatitude ionosphere is subject to intense poleward directed electric fields in the dusk-midnight sector. These electric fields lead to the generation of a latitudinally narrow westward directed flow channel in the subauroral region called a subauroral polarization stream (SAPS). If the magnetic field lines are treated as equipotentials, electrodynamic events such as SAPS are expected to occur simultaneously at magnetically conjugate locations with similar features. In this paper we present simultaneous observations of a SAPS event in both hemispheres made by midlatitude SuperDARN radars with conjugate fields-of-view. We analyze the relation between the geomagnetic conditions and the characteristics of the channels such as latitudinal location, electric field, total potential variations across the channels, and Pedersen current. The results suggest a strong correlation between the strength of the ring current and the latitudinal location of the channel. An inter-hemispheric comparison of the characteristics of the channel indicates that the potential variations across the channels are similar while the electric fields, Pedersen currents and latitudinal widths of the channel exhibit differences that are consistent with equal potential variations. We attribute these differences to seasonal differences in ionospheric conductivity between the hemispheres and magnetic distortion effects in the inner magnetosphere.

Citation: Kunduri, B. S. R., J. B. H. Baker, J. M. Ruohoniemi, L. B. N. Clausen, A. Grocott, E. G. Thomas, M. P. Freeman, and E. R. Talaat (2012), An examination of inter-hemispheric conjugacy in a subauroral polarization stream, J. Geophys. Res., 117, A08225, doi:10.1029/2012JA017784.

\section{Introduction}

[2] Subauroral polarization streams (SAPS) are latitudinally narrow regions of intense westward flows observed in the midlatitude ionosphere observed either just equatorward or at the edge of the auroral electron precipitation boundary [Anderson et al., 1993, 2001; Foster and Burke, 2002; Oksavik et al., 2006; Makarevich and Dyson, 2008; Grocott et al., 2011]. SAPS are considered to be a result of poleward directed subauroral electric fields associated with processes occurring in the inner magnetosphere [Foster, 1995; Foster

\footnotetext{
${ }^{1}$ Bradley Department of Electrical and Computer Engineering, Virginia Polytechnic and State University, Blacksburg, Virginia, USA.

${ }^{2}$ Institute of Geophysics and Extraterrestrial Physics, Braunschweig, Germany.

${ }^{3}$ Department of Physics and Astronomy, University of Leicester, Leicester, UK.

${ }^{4}$ British Antarctic Survey, Cambridge, UK.

${ }^{5}$ Johns Hopkins University Applied Physics Laboratory, Laurel, Maryland, USA.

Corresponding author: B. S. R. Kunduri, 1991 Kraft Dr., Ste. 2019, Blacksburg, VA 24060, USA. (bharatr@vt.edu)

C2012. American Geophysical Union. All Rights Reserved. 0148-0227/12/2012JA017784
}

and Rich, 1998]. A number of terms have been employed in the literature to describe SAPS, which include polarization jets (PJ) [Galperin et al., 1974], subauroral ion drifts (SAID) [Spiro et al., 1979; Anderson et al., 1993], subauroral electric fields (SAEF) [Karlsson et al., 1998] and substorm associated radar auroral surges (SARAS) [Freeman et al., 1992]. The term subauroral polarization stream (SAPS) was introduced [Foster and Burke, 2002] as a broad description of strong westward flows (generally $200 \mathrm{~m} / \mathrm{s}-500 \mathrm{~m} / \mathrm{s}$ ) which are not as intense as those associated with SAID. SAID (also referred to as PJ in some literature) is more localized in latitude than SARAS and SAPS and is an intense enhancement embedded within a SAPS channel where the flows may reach $5 \mathrm{~km} / \mathrm{s}$ in magnitude [Foster and Burke, 2002; Anderson et al., 2001]. A similar phenomenon called auroral westward flow channel (AWFC) has been reported in the literature [Makarevich and Dyson, 2008; Koustov et al., 2006; Parkinson et al., 2003, 2007]. AWFC's are reported to exhibit characteristics similar to that of relatively weak SAID/PJ and are thought to be their poleward manifestations [Parkinson et al., 2003]. SAPS are typically observed in the pre-midnight ionosphere between 18:00 and 02:00 MLT [Spiro et al., 1979; Anderson et al., 2001].

[3] A mechanism was proposed by Anderson et al. [1993] to explain the formation of SAPS. During geomagnetically 
disturbed conditions the equatorward edge of the ion precipitation boundary moves earthward relative to the equatorward edge of the electron precipitation boundary [Anderson et al., 2001; Heinemann et al., 1989]. This leads to the generation of a radial electric field in the inner magnetosphere which maps into the ionosphere along magnetic field lines in the poleward direction. The resulting poleward directed electric field causes an increased westward $\mathbf{E} \times \mathbf{B}$ drift in the midlatitude ionosphere which leads to increased collision frequencies and ion recombination resulting in a depletion in ionospheric plasma in the midlatitude trough [Anderson et al., 2001]. Assuming the main magnetospheric driver supplies the same field-aligned currents, a cumulative effect develops: the depletion of plasma through recombination leads to a decrease in the height integrated conductance and increased electric field and plasma flow velocity [Anderson et al., 2001; Parkinson et al., 2007].

[4] Inter-hemispheric observations of SAPS events provide an opportunity to study conjugate aspects of the dynamics of the Earth's inner magnetosphere during disturbed geomagnetic conditions. SAPS observations at the two ionospheric ends of a closed magnetic field line can be expected to exhibit similarities because large-scale electric fields map with little attenuation along the highly conducting magnetic field lines, any potential difference that arises between the hemispheres should be neutralized by the flow of field-aligned currents [Maeda, 1974; Stening, 1977]. Previous studies related to inter-hemispheric conjugacy have been limited to the auroral zone [Fillingim et al., 2005; Sato and Saemundson, 1987; Frank and Sigwarth, 2003; Østgaard et al., 2004]. Very few studies have focused on the interhemispheric conjugacy exhibited during SAPS events. Foster and Rideout [2007] reported simultaneous observations of SAPS in magnetically conjugate locations while Parkinson et al. [2005] used observations from the TIGER and King Salmon (KSR) SuperDARN HF Radars with magnetically conjugate fields-of-view to study the conjugacy exhibited by an AWFC.

[5] Oksavik et al. [2006] presented the first observations of a SAPS channel in the Wallops Island (WAL) SuperDARN radar and demonstrated the ability of midlatitude SuperDARN radars to make two-dimensional measurements of SAPS/ SAID features with a high temporal resolution. An analysis of a SAPS channel observed by six midlatitude SuperDARN HF radars simultaneously over six hours of magnetic local time is presented in Clausen et al. [2012]. In the current paper we present a detailed analysis of the conjugacy exhibited during a SAPS event that occurred on Aug 4, 2010, using observations from midlatitude SuperDARN radars. This same event was studied by Grocott et al. [2011]. The primary focus of Grocott et al. [2011] was the influence of magnetospheric dynamics and solar wind-magnetosphere coupling on the characteristics of a SAPS channel (observed by the Falkland Islands (FIR) SuperDARN radar in the Southern hemisphere) such as its location and velocity. In the current paper we focus on the inter-hemispheric aspects of the same event using Northern hemisphere observations from WAL and Blackstone (BKS) SuperDARN radars whose fields-of-view are magnetically conjugate to that of the FIR radar. We present an analysis of the inter-hemispheric differences and similarities observed in the features of the SAPS channels.

\section{Data Sets}

\subsection{SuperDARN HF Radars}

[6] The primary data used in this study were measurements of the Doppler velocities associated with ionospheric plasma drift observed by HF radars of the Super Dual Auroral Radar Network (SuperDARN) located at the midlatitudes in the Northern hemisphere (WAL and BKS) and the Southern hemisphere (FIR). The SuperDARN network is an international chain of radars covering both high and midlatitudes in both the Northern and Southern hemispheres. Currently there are 19 radars in the Northern hemisphere and 10 radars operating in the Southern hemisphere with more radar builds underway or planned. SuperDARN radars observe coherent backscatter from decameter-scale irregularities aligned along the magnetic field. The Doppler shift of the backscattered signal is proportional to the line-of-sight component of the $\mathbf{E} \times \mathbf{B}$ plasma drift in the scattering region [Ruohoniemi et al., 1987]. In the standard operating mode the radars use an array of electronically phased antennas that can be steered through 16 beam directions across an azimuth sector of $50^{\circ}$. The radar dwells for 3.5 or $7 \mathrm{~s}$ on each beam along which line-of-sight measurements of the velocity are obtained. The radar dwell time corresponds to the completion of a full azimuth scan in 1 or $2 \mathrm{~min}$.

\subsection{Other Data Sets and Models}

[7] The mapping of SuperDARN Doppler measurements between hemispheres was achieved using the IGRF model for internal sources and Tsyganenko models-T96 [Tsyganenko and Stern, 1996], T01 [Tsyganenko, 2002] and T04S [Tsyganenko and Sitnov, 2005] for external (magnetospheric) current sources. The external contributions to the magnetospheric magnetic field are specified by Tsyganenko models through mathematical formalism and empirical modeling. Certain geomagnetic indices such as the Dst index and interplanetary magnetic field measurements are required as inputs to the Tsyganenko models. The Dst index is indicative of the strength of the ring current and is taken from selected magnetometer stations near the equator [Sugiura, 1964]. For the purposes of analyzing the geomagnetic conditions, the Sym-H and Asym-H indices which are indicative of the strengths of the ring-current and the asymmetric ring current respectively [Iyemori, 1990] were used instead of the Dst index. The Sym-H and Asym-H indices are preferred because of their higher temporal resolution of 1-minute compared to the 1-hour resolution of the Dst index. These indices were accessed through the Geomagnetic Data Service - Kyoto, Japan. The IMF and solar-wind conditions such as the solar wind dynamic pressure and the IMF- $B_{Z}$ were accessed from the OMNI 2 data set at the National Space Science Data Center (NSSDC) [King and Papitashvili, 2005].

[8] The ion and electron energy flux data measured by the $\mathrm{SSJ} / 4$ instrument [Hardy, 1984] on-board the Defense Meteorological Satellite Program (DMSP) F18 spacecraft were used along with the Feldstein-Starkov statistical auroral 


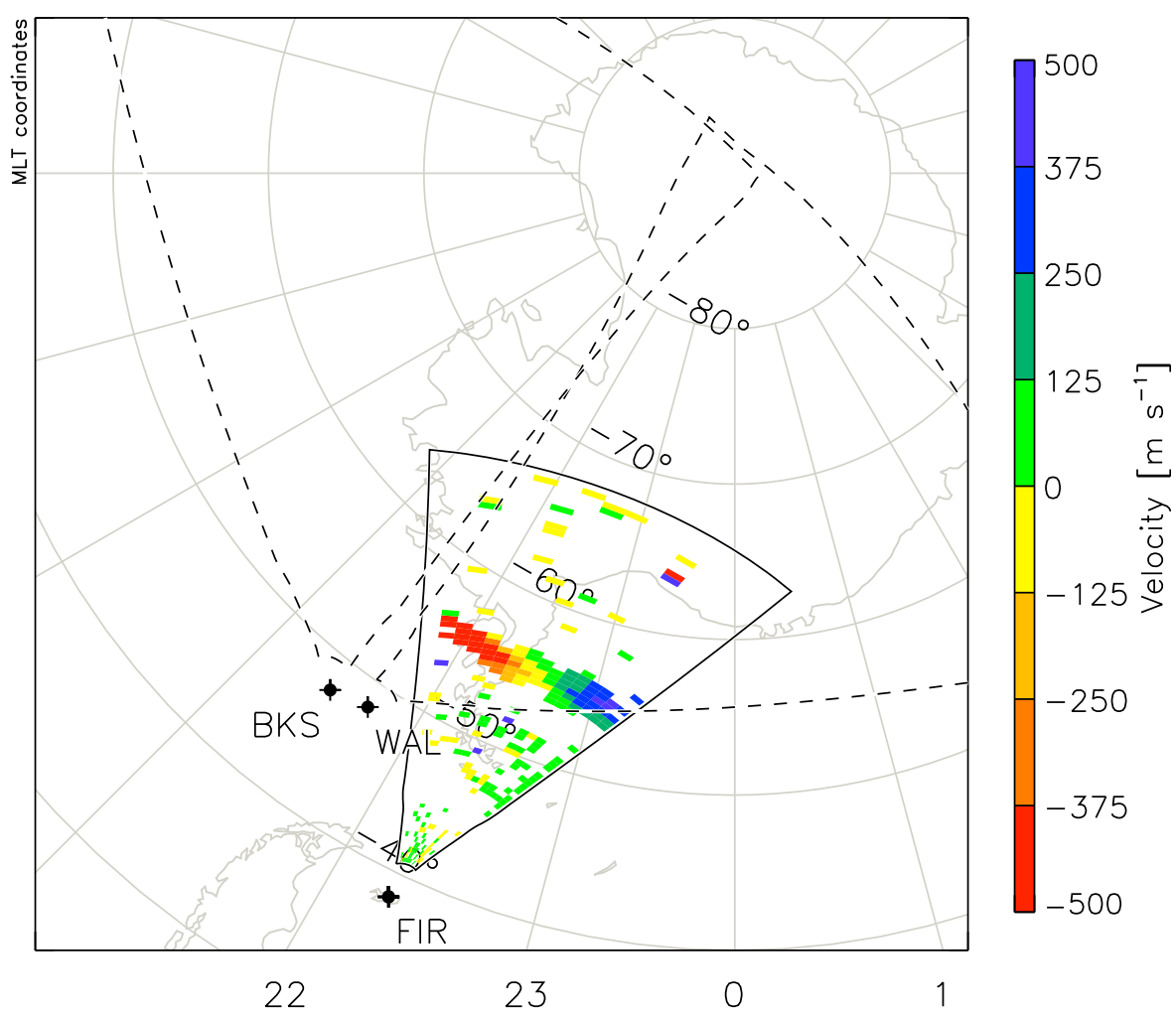

Figure 1. FIR radar observations of the line-of-sight Doppler velocities measured during the 1-minute azimuth scan beginning at 02:30 UT on August 4,2010. The measurements are overlayed on a grid of magnetic latitude - magnetic local time. The velocity is scaled according to the color bar on the right. The solid outline represents the field-of-view of the FIR radar and the dashed outlines represent the fields-of-view of the BKS and WAL radars projected into the Southern hemisphere.

oval models [Feldsten and Starkov, 1967] to predict the locations of the ion and electron auroral ovals. The SSJ/4 instrument provides 1-second resolution measurements of ion and electron energy fluxes between $30 \mathrm{eV}$ and $30 \mathrm{KeV}$ [Hardy, 1984]. The electron flux data were also employed to estimate the height integrated Pedersen conductivity as described by Robinson et al. [1987]. DMSP Special Sensor for Ions, Electron and Scintillation (SSIES) thermal plasma instrument package [Rich and Hairston, 1994] includes the Ion Drift Meter (IDM) which measures the thermal ion velocity in the horizontal and vertical directions relative to spacecraft velocity. The data from IDM are used during favorable conjunctions to verify the observations made in SuperDARN radars.

\section{Observations}

[9] On August 42010 from 00:30 UT to 04:30 UT a region of high velocity backscatter was observed simultaneously by the WAL and BKS radars in the Northern hemisphere and the FIR radar in the Southern hemisphere. In this section we examine the nature of the backscatter observed by these radars and verify that this backscatter was indeed from SAPS channels. The FIR radar measurements from the same event period were studied independently by Grocott et al. [2011].

[10] Figure 1 shows measurements of line-of-sight Doppler velocity made by the FIR radar plotted in magnetic latitude
(MLAT) vs magnetic local time (MLT) coordinates for the scan beginning at 02:30 UT. The velocity is scaled according to the color bar on the right of the figure. The field-of-view of the FIR radar is identified in solid black lines. The dashed black lines mark the fields-of-view of the WAL and BKS radars projected from the Northern hemisphere into the Southern hemisphere. It can be observed that a significant portion of the field-of-view of the WAL radar in the Northern hemisphere is magnetically conjugate to the fieldof-view of the FIR radar in the Southern hemisphere, while the field-of-view of the BKS radar extends the coverage to the west of the conjugate region. In a similar manner Figure 2 presents measurements of the line-of-sight Doppler velocities measured by the BKS and WAL radars in the Northern hemisphere at the same time. The dashed black lines mark the field-of-view of the FIR radar projected from the Southern to the Northern hemisphere. The backscatter observed in the BKS and WAL radars appears different because of the different operating frequencies of the radars during the event (BKS $\sim 9 \mathrm{MHZ}$ and WAL - varied between 9 and $16 \mathrm{MHz}$ ).

[11] In Figure 1 a latitudinally narrow region of backscatter, about $2^{\circ}$ in latitudinal width with line-of-sight velocity $\left(V_{L O S}\right)$, varying in magnitude from $150 \mathrm{~m} / \mathrm{s}$ to $500 \mathrm{~m} / \mathrm{s}$ was observed by the FIR radar centered on $-57^{\circ}$ magnetic latitude and extending almost across the entire field-of-view. The red colored portion of the backscatter in the figure corresponds to 


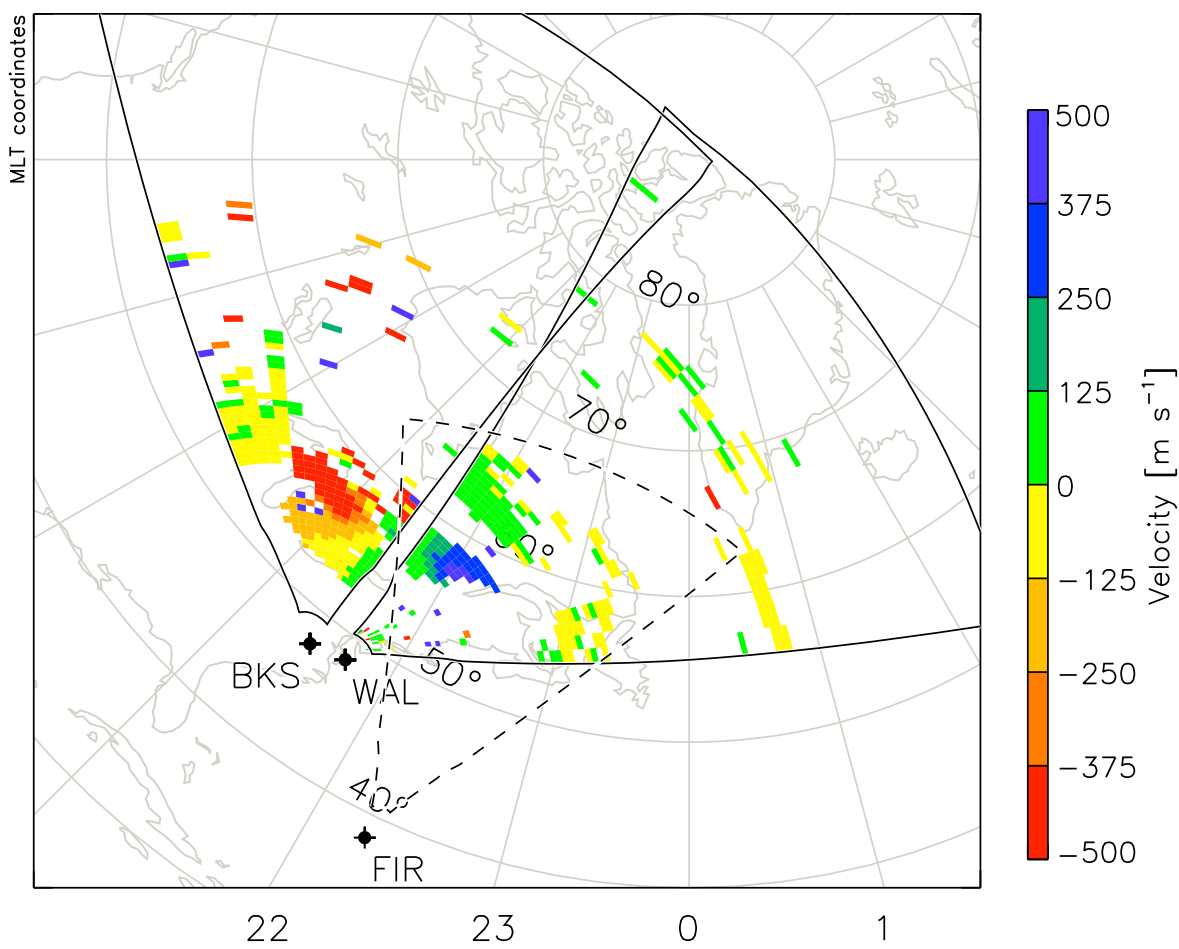

Figure 2. WAL and BKS radar observations of the line-of-sight Doppler velocities measured during the azimuth scan at 02:30 UT on August 4, 2010. The measurements are overlayed on a grid of magnetic latitude - magnetic local time. The velocity is scaled according to the color bar on the right. The solid outlines indicate the fields-of-view of the WAL and BKS radars and the dashed outline represents the field-ofview of the FIR radar projected into the Northern hemisphere.

negative $V_{L O S}$ and indicates flow away from the radar. The blue colored backscatter corresponds to positive $V_{L O S}$ and indicates flow toward the radar. A systematic variation in the direction of $V_{L O S}$ across the field-of-view of the FIR radar can be seen. The measured $V_{L O S}$ is directed toward the radar in the eastward-oriented beams (beams 11-16), then gradually passes through zero across the poleward-oriented central beams (beams 8-10) and in the westward-oriented beams (beams 1-7) the direction of $V_{L O S}$ is away from the radar. This indicates that the actual direction of the flow in the ionosphere is predominantly westward and resembles a SAID channel.

[12] Simultaneously in the Northern hemisphere, the BKS and WAL radars made observations of a similar narrow region of high-velocity backscatter. The feature extended from $55^{\circ}$ to $60^{\circ}$ in magnetic latitude and was predominantly observed in beams $5-13$ of the BKS radar and beams 2-5 of the WAL radar (beams are numbered from west to east). The observations in the Northern hemisphere indicate the presence of a high-velocity narrow channel embedded within a broader channel (about $5^{\circ}$ to $6^{\circ}$ in latitudinal width) of comparatively lower velocity, similar to the characteristics of SAID and SAPS [Oksavik et al., 2006]. It should be noted that in the Southern hemisphere observations were dominated by a narrow SAID-like feature, without a surrounding SAPS. The $V_{L O S}$ observed in the BKS and WAL radars exhibit an orderly east to west variation similar to the observations in the Southern hemisphere. This indicates the flows in the Northern hemisphere are also predominantly westward.

[13] Other characteristics of this region will be explored further to demonstrate that this backscatter is indeed from a SAPS/SAID channel in both the hemispheres.

\subsection{Location of the SAPS Scatter Region}

[14] Previous studies [Anderson et al., 1993; Foster and Vo, 2002] have identified SAPS as lying either just equatorward or at the edge of the equatorward boundary of the electron auroral oval. The purpose of this section is to characterize the location of the scatter region and demonstrate that the scatter is subauroral.

[15] Figure 3 presents $V_{L O S}$ observed during an azimuth scan in the BKS radar beginning at 03:32 UT on August 4, 2010. It is overlayed on a map marked in MLT vs magnetic latitude. A DMSP F18 satellite pass in the northern hemisphere around the time of the scan is also shown in the figure. The black dots represent the location of the spacecraft at the marked instance of time (in UT). Data from the ion drift meter instrument onboard the satellite is also overlayed on the map.

[16] We use data from the SSJ/4 instrument [Hardy, 1984] on board the DMSP F18 spacecraft to identify the equatorward electron and ion auroral oval boundaries and compare them with the location of the radar backscatter region under study. The first and second panels of Figure 4 present the time variations in SSJ/4 total ion energy flux data across the 


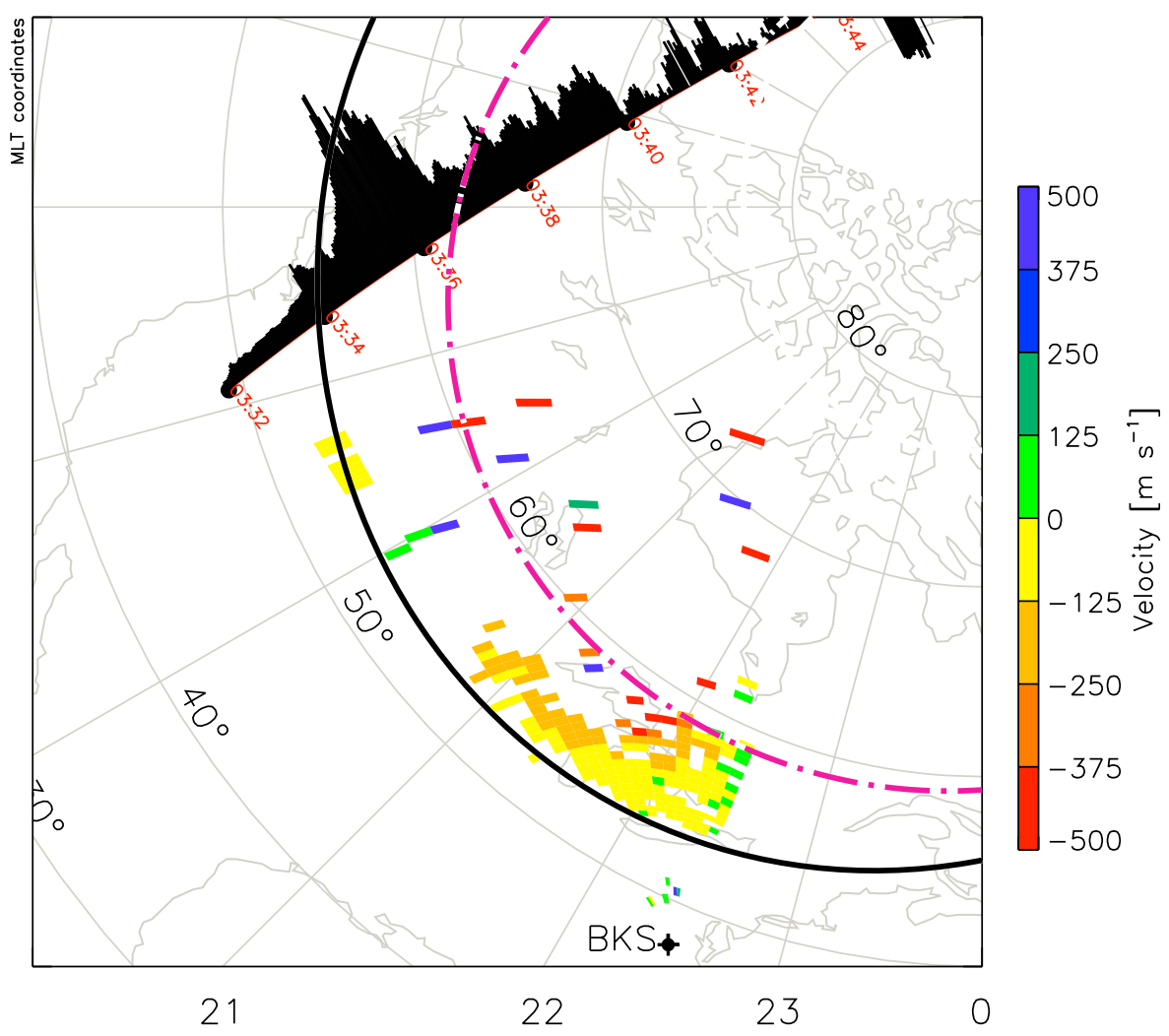

Figure 3. Line-of-sight velocity plot for a full scan of BKS radar at 03:32 UT on August 4, 2010, displayed versus magnetic latitude and magnetic local time. The velocity of the scatter is scaled according to the color bar on the right. Overlayed on the map is the DMSP F18 SSIES ion drift meter data at the mentioned instance of time (in UT). The solid black and the dashed purple curves mark the equatorward and poleward boundaries of the backscatter respectively. Further details are discussed in the text.

entire energy spectrum and the ion energy spectrograms respectively. The third and fourth panels represent the same for electron energy flux. The solid black line overlayed on the first and second panels of Figure 4 and the dotted purple line overlayed on the third and fourth panels mark the times at which the spacecraft crosses the equatorward boundaries of the ion and electron precipitation respectively. The boundaries were identified in a manner similar to the criteria described in Gussenhoven et al. [1981] for identifying the equatorward electron auroral boundary, such as a sharp increase in the total number flux $\left(\mathrm{J}_{\text {Ntot }}\right)$ and energy flux $\left(\mathrm{J}_{\text {Etot }}\right)$ of electrons and $\mathrm{J}_{\text {Ntot }}$ reaching values greater than $10^{7}\left(\mathrm{~cm}^{2} \mathrm{sr} \mathrm{s}\right)^{-1}$ on encountering the boundary. The magnetic latitudes of the equatorward boundaries of ion and electron auroral ovals are indicated in Figure 4. The shaded region in the figure represents the location of the backscatter region observed by the BKS radar and clearly lies between the precipitation boundaries.

[17] The backscatter region in Figure 3 shows $V_{L O S}$ varying between -200 and $-500 \mathrm{~m} / \mathrm{s}$ between $20: 00$ and 22:00 MLT. This region was about $6^{\circ}-7^{\circ}$ in latitudinal width and extended between $53^{\circ}$ and $59^{\circ}$ magnetic latitude. The solid black and the dotted purple curves in Figure 3 mark the equatorward and poleward edges of the high velocity backscatter region. These curves are marked by adjusting the Feldstein statistical auroral oval models [Feldsten and
Starkov, 1967]. This region of backscatter is indicated in Figure 4 as the shaded region. From Figures 3 and 4, it can be observed that the radar backscatter is confined to the area that lies between the ion and electron precipitation boundaries. The association of the SAPS like feature in the radar observations with the particle precipitation boundaries is similar to the results presented in previous studies [Anderson et al., 1993, 2001; Foster and Vo, 2002].

[18] A similar analysis is done in the Southern hemisphere and the results are presented in Figures 5 and 6 . The $V_{L O S}$ data for an azimuth scan beginning at 03:00 UT in the FIR radar are shown in Figure 5. The radar backscatter region was only about $3^{\circ}$ in latitudinal width and extended between $55^{\circ}$ and $58^{\circ}$ magnetic latitude. Figure 6 presents the DMSP F18 ion and electron energy flux measurements in the Southern hemisphere near the field-of-view of the FIR radar in the same format as Figure 4. The equatorward ion and electron precipitation boundaries were identified in a manner similar to the Northern hemisphere. The shaded region in the figure indicates the location of the backscatter region observed by the FIR radar. The location of this region with respect to the particle precipitation boundaries suggests that the SAPS-like feature was observed equatorward of the electron auroral oval and poleward of the ion oval.

[19] The data from DMSP ion drift meter (shown in Figures 3 and 5) also shows the presence of narrow channels 

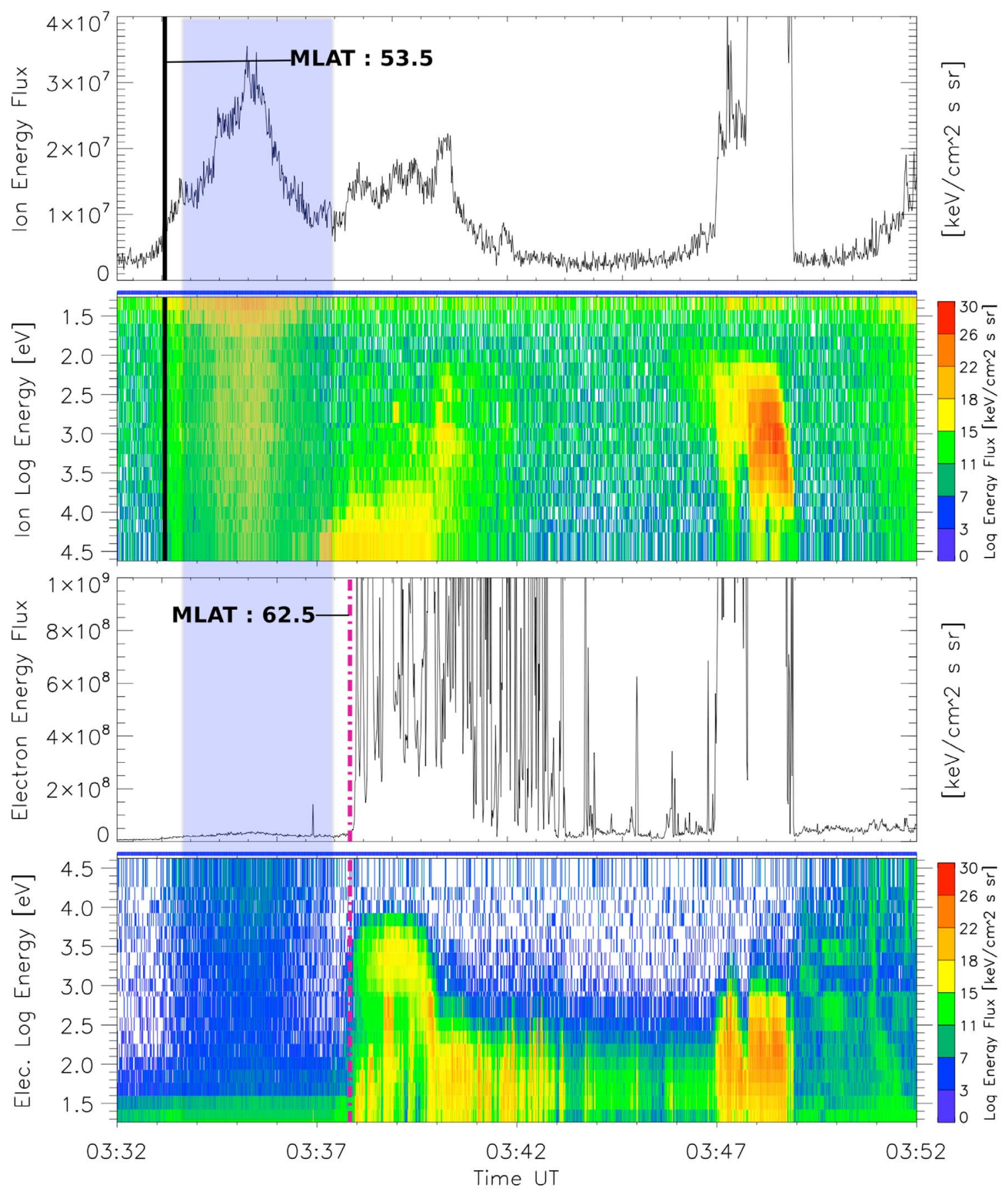

Figure 4. Time series data from SSJ/4 instrument onboard DMSP F18 satellite corresponding to the pass presented in Figure 3. (top to bottom) Total ion energy flux across the entire energy spectrum, Ion energy spectrogram, scaled according to the color bar on the right, total electron energy flux across the entire energy spectrum, and electron energy spectrogram in a format similar to the first two panels. The solid black lines and the dotted purple lines overlayed on the panels indicate the time at which the satellite crosses the equatorward boundaries of the ion and electron precipitation respectively. The shaded region in all the panels represents the location of the backscatter region observed in the radar.

of high velocity, latitudinally collocated with the radar observations of similar flow channels in both hemispheres. The DMSP ion drift meter data thus validates the observations made in the BKS and FIR radars. It can be noted from Figure 3 that the high-velocity channel observed in the
DMSP ion drift meter data is slightly broader than the channel observed in the BKS radar. This can be associated with the tendency of the flow channel to broaden with decreasing MLT from midnight to dusk [Anderson et al., 1991; Erickson et al., 2011]. Major differences were 


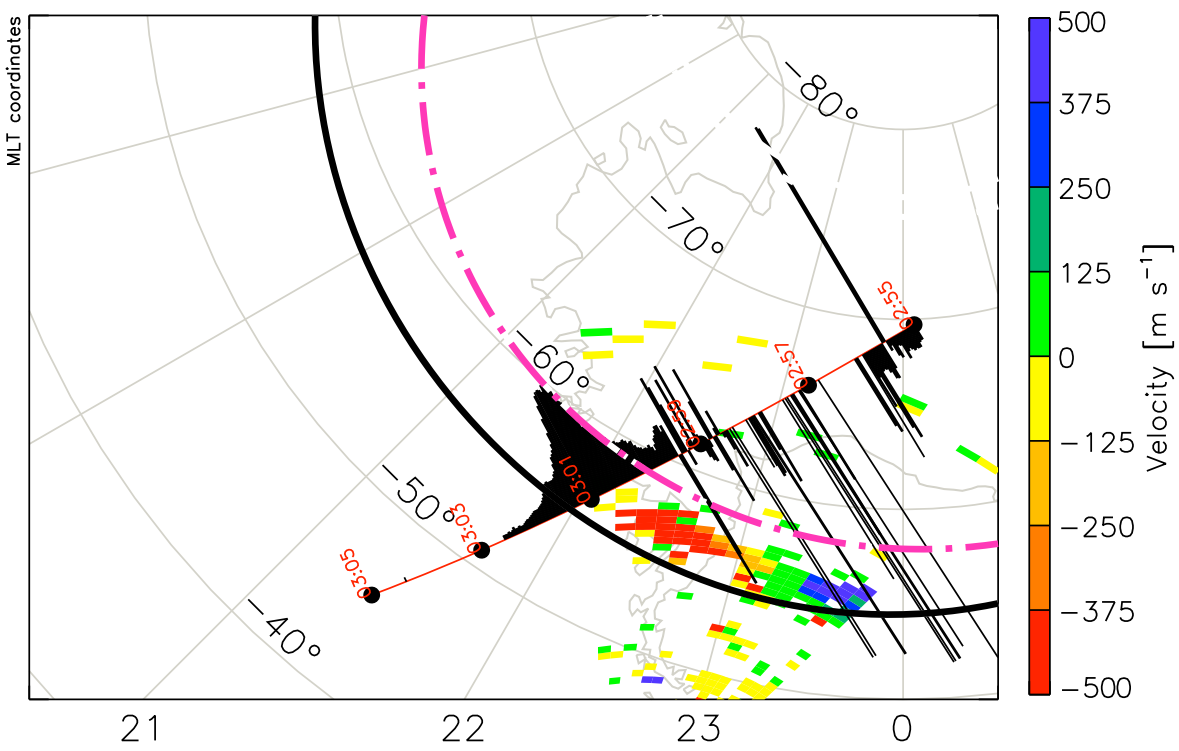

Figure 5. Line-of-sight velocity plot for a full scan of FIR radar and a DMSP F18 SSIES ion drift meter overlay at 03:00 UT on August 4, 2010 (in the same format as Figure 3).

observed between the hemispheres in respect of the location of the equatorward edges of the ion and electron precipitation boundaries. The equatorward edges of the ion and electron precipitation boundaries near the scatter region were observed to be located near $53^{\circ}$ MLAT and $60^{\circ}$ MLAT respectively, in the Northern hemisphere. The equatorward edges of the electron and ion precipitation boundaries were located near $-58^{\circ}$ and $-55^{\circ}$ MLAT respectively, in the southern hemisphere. This indicates inter-hemispheric differences and will be discussed further in later sections. Although the observations in opposite hemispheres were made at different times (a 30 minute difference), the stability of the SAPS/SAID features (the latitudinal location and width of the channels do not vary significantly as can be seen in the range-time plots shown in Figure 10, presented later) through this time period and their obvious association with the precipitation boundaries indicates sufficient permanence to discuss conjugacy. Moreover the location of the equatorward edges of the precipitation boundaries was examined in both hemispheres using other DMSP passes as well (such as the DMSP F18 pass at 01:50 UT in the Northern hemisphere and at 01:15 UT in the Southern hemisphere). It was observed that the separation between the boundaries was consistently wider in the Northern hemisphere compared to the Southern hemisphere.

[20] In summary, the electron energy flux data shown in Figures 4 and 6 indicates that the latitudinally narrow regions of high westward velocity backscatter shown in Figures 3 and 5 are subauroral, satisfying the first requirement for the east-west elongated channels of radar backscatter to be associated with SAPS.

\subsection{Direction and Magnitude of Flows in the Channel}

[21] In this section we present an analysis of the flow velocity within the SAPS channels in both hemispheres.

[22] Figure 7 presents the $V_{L O S}$ measured in each beam plotted as a function of the beam azimuth and time for both the FIR (top panel) and BKS (bottom panel) radars. The magnetic azimuth of the beams varied from $-20^{\circ}$ to $16^{\circ}$ for the FIR radar and from $-40^{\circ}$ to $-9.5^{\circ}$ for the BKS radar. In the figure each colored dot corresponds to a $V_{L O S}$ measured at that magnetic azimuth. The color of the dots indicates the time of measurement, scaled according the color bar on the right with red (blue) indicating earlier (later) occurrence. From the figure it can be observed that the $V_{L O S}$ in the FIR radar were negative in the westward direction (magnetic azimuth $<0$ ), positive in the eastward direction (magnetic azimuth $>0$ ) and that $V_{L O S}$ passed through zero near the poleward direction. A similar dependence of $V_{L O S}$ on the magnetic azimuth of the beam was observed in the BKS radar, but the observations were limited to westward direction due to the orientation of the beams. This dependence of $V_{L O S}$ on magnetic azimuth also conforms to the predominantly westward nature of flow across the field-of-view of the radars and indicates an approximately sinusoidal dependence of $V_{L O S}$ on magnetic azimuth. These observations are consistent with the results presented in Grocott et al. [2011].

[23] To demonstrate the sinusoidal variation exhibited by the $V_{L O S}$ with magnetic azimuth, the median values of $V_{L O S}$ (represented by the thick black dots) were calculated over the time interval 02:15 UT to 03:45 UT (interval with good conjugate observations) at every magnetic azimuth. Sine curves (indicated by the dotted lines in Figure 7) were then fit to these median $V_{L O S}$. The insets in both the panels present the same curves along with the median $V_{L O S}$ (black dots) for an extended magnetic azimuth range of $-90^{\circ}$ to $90^{\circ}$. From the figure it can be observed that the median $V_{L O S}$ exhibit a good adherence to the sine curves, except for some deviation at higher magnetic azimuths (which correspond to beams at the edges of the field-of-view). This could be due to the lack of data at certain range gates in these beams as seen in the azimuth scan plots presented in Figures 1 and 2. Another possibility is that over the larger longitudinal scales there is significant curvature in the convection such that the flow cannot be considered strictly uniform [Freeman et al., 1991]. 

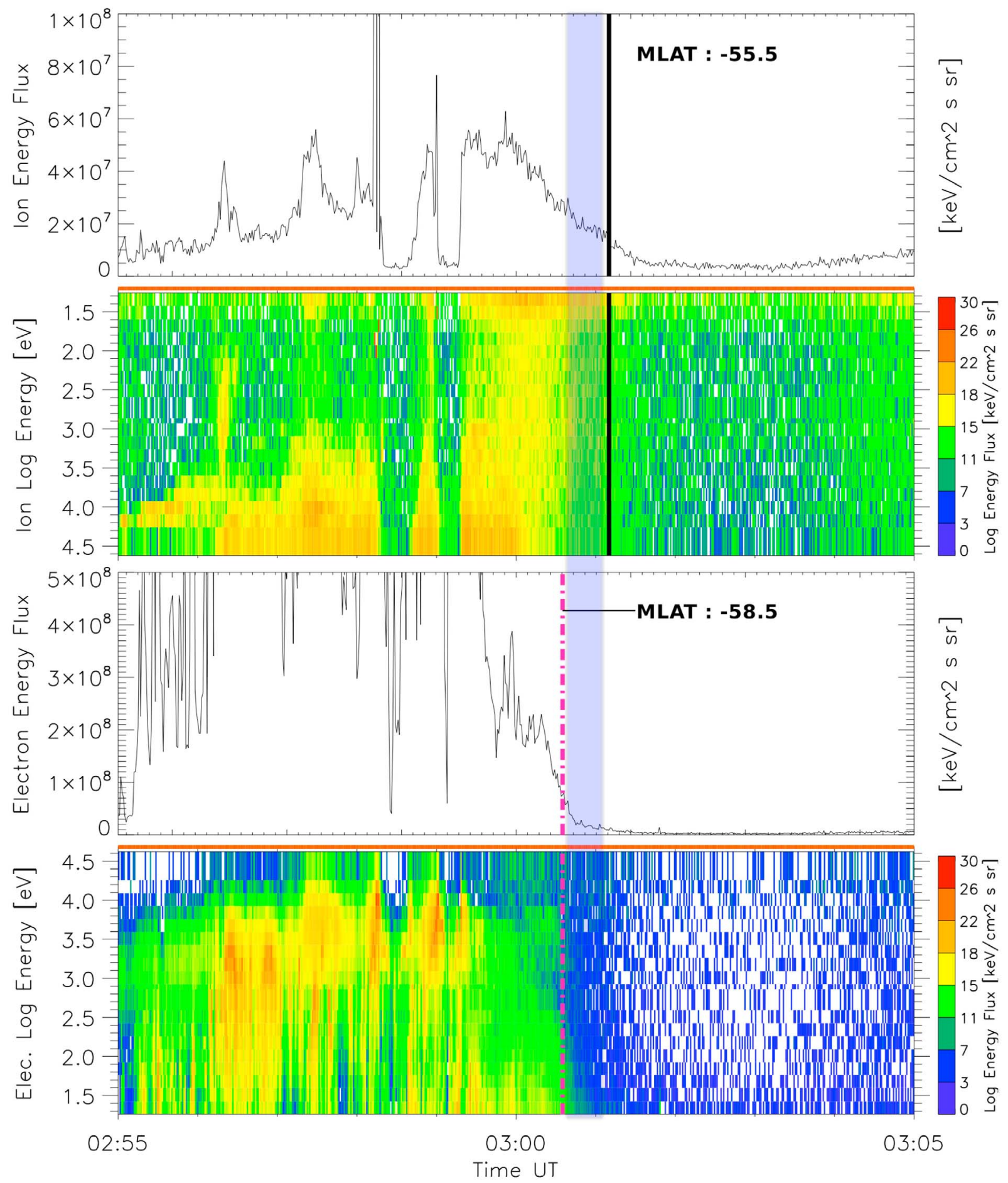

Figure 6. Time series data from SSJ/4 instrument onboard DMSP F18 satellite corresponding to the pass shown in Figure 5 (in the same format as Figure 4).

[24] From a sine curve fitting of median $V_{L O S}$, the bearing (from median $V_{L O S}$ ) of the flows was determined to be $\sim-92^{\circ}$ for the Southern hemisphere. Figure 8 shows the direction and magnitude of the SAPS flows (at the location in the flow channel where $V_{L O S}$ was highest) estimated by projecting the $V_{L O S}$ along the median direction of flow in each beam of the FIR radar. These correspond to an azimuth scan beginning at 02:46 UT. The velocities across the beams were found to vary between $2.7 \mathrm{~km} / \mathrm{s}$ and $3 \mathrm{~km} / \mathrm{s}$. This variability could be due to the MLT difference (about 1 hour) across the field-of-view of FIR radar [Foster and Vo, 2002] or any variations in ionospheric conductivity. Since the variability is small compared to the magnitude, a median value of the velocity magnitude across the beams was calculated which came out to be $\sim 2.8 \mathrm{~km} / \mathrm{s}$. The median velocity across the beams would provide a means to make inter-hemispheric 


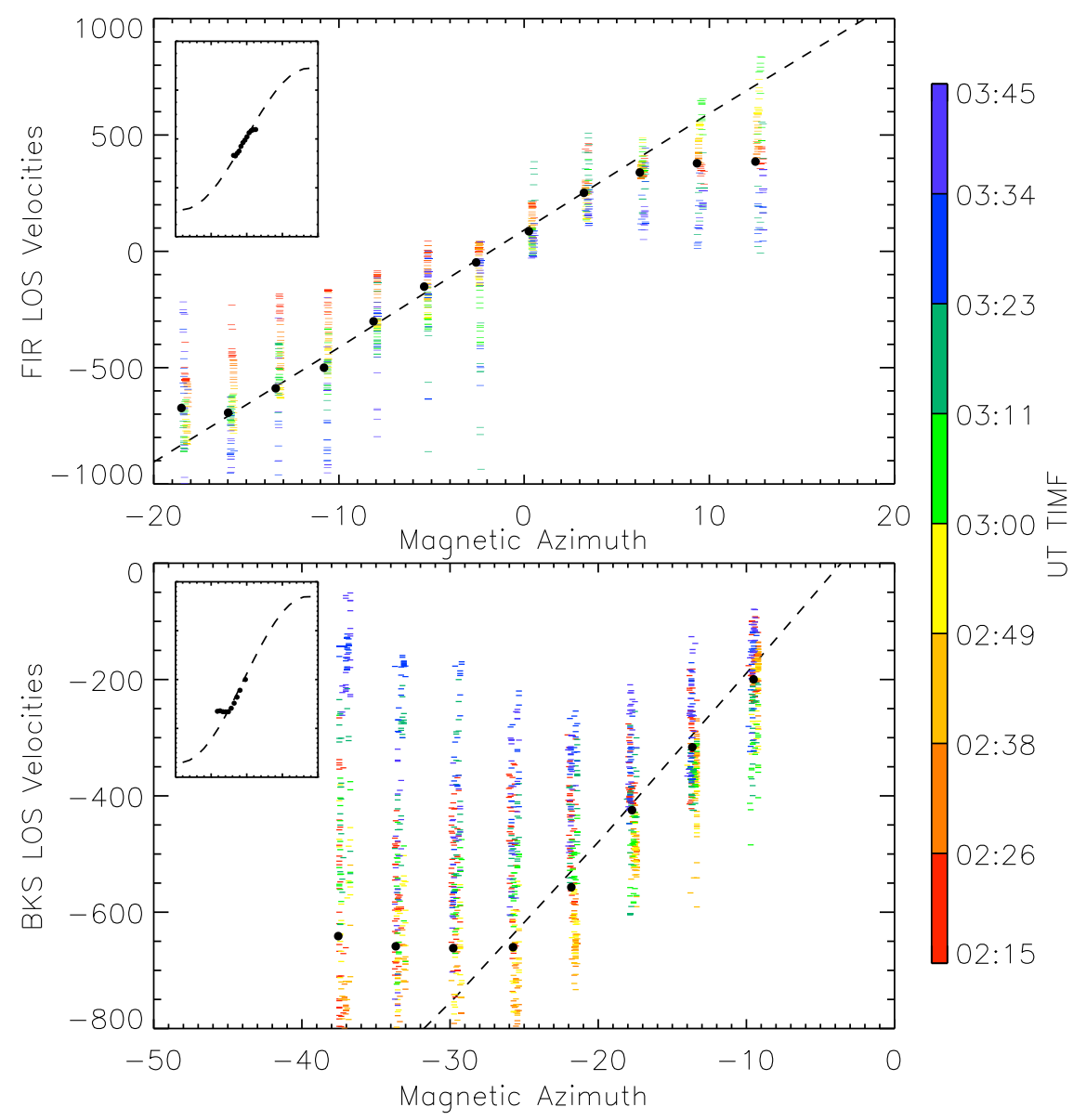

Figure 7. Variations in the line-of-sight velocities with time plotted against magnetic azimuth for the (top) FIR and (bottom) BKS radars. The small colored dots are color coded according to the timescale indicated on the right. The thicker black dots indicate the median values of $V_{L O S}$ at every magnetic azimuth. The dotted lines represent a sine curve fit to the median $V_{L O S}$. The same sine curves for the range $-90^{\circ}$ to $90^{\circ}$ are shown in the insets.

comparisons. A similar analysis in the Northern hemisphere showed that the bearing of the flows was $\sim-94^{\circ}$ and the median value of velocity magnitude was about $1.7 \mathrm{~km} / \mathrm{s}$. The sine curve fitting showed that the flow direction in both the hemispheres was practically westward and that the velocities reached magnitudes greater than $2 \mathrm{~km} / \mathrm{s}$.

[25] The large scale fitting to obtain an overall SAPS velocity will lead to missing finer variations in the flow. However, the main goal of this paper is to provide an overview of inter-hemispheric differences in the SAPS channels and this will not considerably affect our results. The SAPS velocity magnitude calculated this way will be referred to as 'estimated zonal' velocity from now on. From this analysis it is clear that the SAPS velocity is very nearly zonal with a considerable difference in magnitude between the hemispheres. A detailed inter-hemispheric comparison of the estimated zonal velocities is presented in the next section alongside other characteristics of the SAPS channel.

\subsection{Geomagnetic Conditions and Their Influence on the Channel}

[26] A SAPS event is generally associated with disturbed geomagnetic conditions [Foster and Burke, 2002; Anderson et al., 2001, 1993]. It is therefore important to analyze the solar-wind and magnetospheric conditions prevalent during this event to investigate their effects on the flows.

[27] Measurements of the latitudinally narrow region of high velocity backscatter were made during the course of a moderate geomagnetic storm that occurred between 3-5 August 2010. On August 32010 at around 19:00 UT the Dst index showed a sudden increase to $22 \mathrm{nT}$ indicating storm sudden commencement and marking the beginning of the storm. Figure 9 presents the observations of the solarwind and IMF conditions from 00:00 UT to 06:00 UT on August 42010 during the time of the observations. During this event the IMF- $\mathrm{B}_{Z}$ varied between $-12 \mathrm{nT}$ and $12 \mathrm{nT}$ and exhibited gradual south-north transition with short northward excursions. The $\mathrm{B}_{Y}$ component of the IMF stayed predominantly negative with a gradual strengthening in magnitude with short excursions to positive values, reaching a peak value of $-15 \mathrm{nT}$. The IMF-B $\mathrm{B}_{X}$ varied between -10 and $8 \mathrm{nT}$. The solar-wind speed was relatively stable at around $600 \mathrm{~km} / \mathrm{s}$ and the solar wind dynamic pressure varied between 6-10 $\mathrm{nPa}$.

[28] The top three panels of Figure 10 present the geomagnetic conditions. The first panel presents the Kp index 


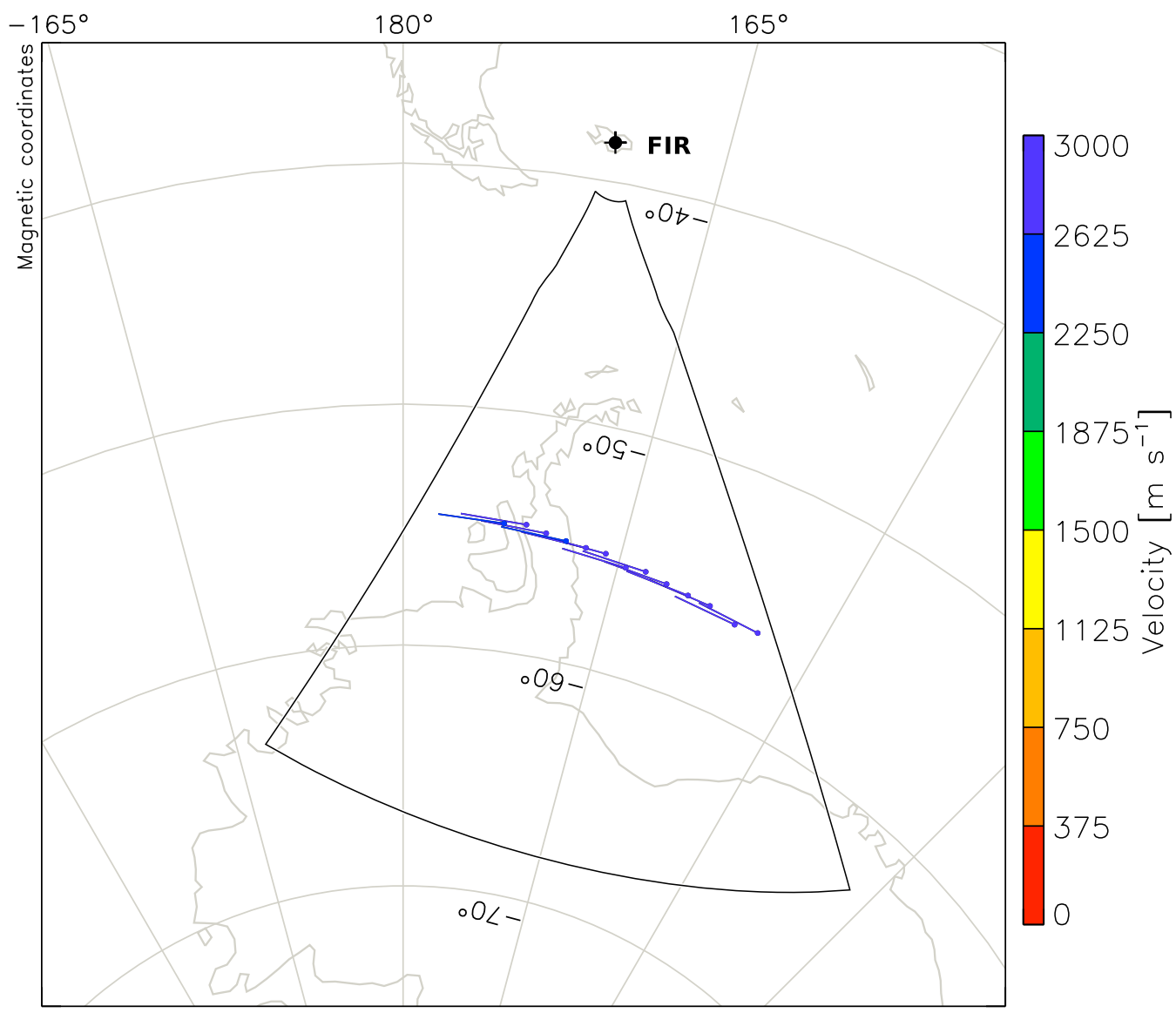

Figure 8. Direction and magnitude of the SAPS flows in each beam of the FIR radar, determined as described in the text. These correspond to the azimuth scan beginning at 02:46 UT on August 4, 2010 and are overlayed on a map marked in magnetic coordinates. The velocity is scaled according to the color bar on the right.

which varied between $4-6$ during the interval. The second and third panels present the Sym-H and the Asym-H index. These are indicative of the strength of the symmetric ring current and the partial ring current respectively [Iyemori, 1990]. It can be observed that the Sym-H index reached a peak value of about $-80 \mathrm{nT}$ around 01:30 UT and varied between -50 and $-70 \mathrm{nT}$ from then on. The Asym- $\mathrm{H}$ index reached a peak value of $120 \mathrm{nT}$ and its variations were roughly correlated with Sym-H index for a major period during the interval. The Asym-H and Sym-H indices showed a large degree of variability suggesting alternating periods of intensification and weakening of the ring current.

[29] The AE index reached a peak value of $1200 \mathrm{nT}$ at $\sim 0100 \mathrm{UT}$ and varied between $250 \mathrm{nT}$ and $800 \mathrm{nT}$ during the rest of the interval. An examination of the auroral indices (AE, AL, AU and AO) and ground based magnetometer data from the THEMIS magnetometer chain (data not presented here) suggest that the observations in this study occurred during an interval of sporadic substorm activity. The presence of substorms during the interval and the location of the SAPS/SAID channel between the equatorward edges of the ion and electron precipitation boundaries, support the concept that the earthward boundaries of ion and electron precipitation separate following substorm onset, thereby leading to the generation of SAPS [Anderson et al., 1993,
2001]. A detailed analysis of the influence of substorm activity on the SAPS channel during this event is presented in Grocott et al. [2011].

[30] The fourth, fifth and sixth panels of Figure 10 present the $V_{L O S}$ observed in beam 11 of the BKS radar, beam 3 of the WAL radar and beam 5 of the FIR radar respectively, plotted versus magnetic latitude and time. These plots present the temporal variability in latitudinal position, width and velocities exhibited by the channel in both hemispheres. The SAPS/SAID channel can be observed predominantly between 01:00 UT and 04:30 UT in all three radars. The observations clearly indicate that the width and the latitudinal location of the channel varied with time and in general the channel was consistently narrower in the Southern hemisphere. The solid lines inside the SAPS channel (black - BKS beam 11, red- WAL beam 3 and black- FIR beam 5) mark the latitudes at which the observed $V_{L O S}$ were maximum. These latitudes will be referred to as Lat $\mathrm{MAX}$ from here on. A preliminary look at Lat ${ }_{\text {MAX }}$ in each radar and the Asym- $\mathrm{H}$ index shows that Lat ${ }_{\mathrm{MAX}}$ moves equatorward as Asym- $\mathrm{H}$ increases and poleward when Asym-H decreases.

[31] A correlation analysis was performed to understand the influence of geo-magnetic conditions such as the Asym- $\mathrm{H}$ index (partial ring current) on latitudinal and estimated zonal velocity variations in the SAPS channel in both hemispheres. 

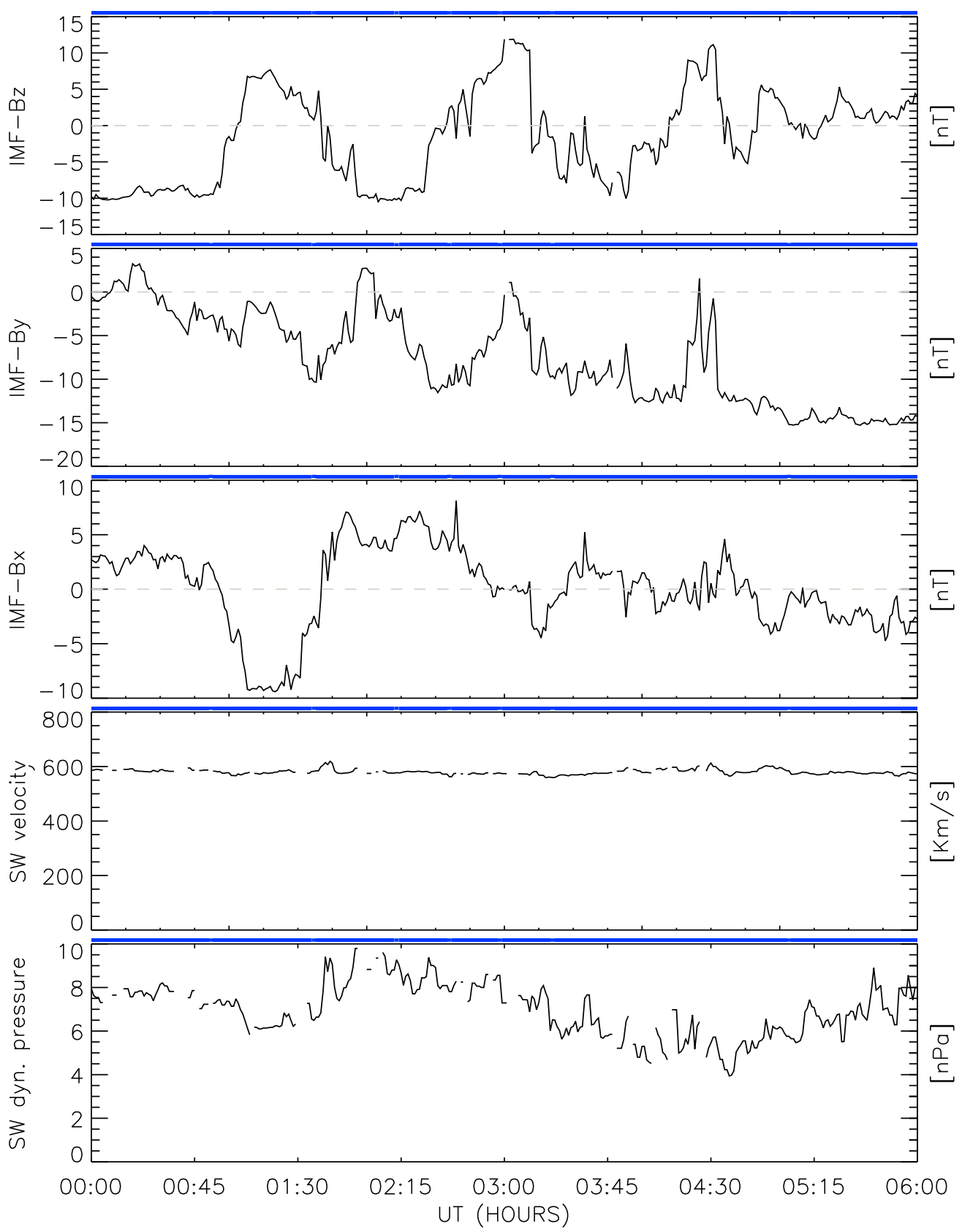

Figure 9. Time variations of solar-wind and IMF data on August 4, 2010 from 00:00 UT to 06:00 UT. (top to bottom) ' $\mathrm{Z}$ ', ' $\mathrm{Y}$ ' and ' $\mathrm{X}$ ' components of interplanetary magnetic field, solar wind velocity, and solar wind dynamic pressure, taken from the OMNI 2 data set.

The top-left and the top-right panels of Figure 11 present scatter plots of the variations in Lat ${ }_{\text {MAX }}$ and estimated zonal velocities within the SAPS channel observed in the BKS radar as a function of Asym-H index. The correlation coefficients were found to be 0.65 and 0.57 respectively. The bottom-left and the bottom-right panels present scatter plots of Lat ${ }_{\text {MAX }}$ and estimated zonal velocity variations observed in the FIR and BKS radars. The correlation coefficients were calculated to be -0.83 and 0.66 respectively. The correlation coefficients presented in this study were verified to be statistically significant using the student's t-test (with probability of unlikely occurrence, $\mathrm{P} \ll 0.01$ ).
[32] Results presented in Figure 11 suggest that there exists a good correlation between latitudinal variations in the channel and the strength of the asymmetric ring current. However, the estimated zonal velocities exhibit a comparatively weaker correlation between the hemispheres and with the asymmetric ring current. The results of the correlation analysis are summarized in Table 1.

\section{Discussion}

[33] In the previous section observations of a SAPS channel made simultaneously by the BKS and WAL radars 


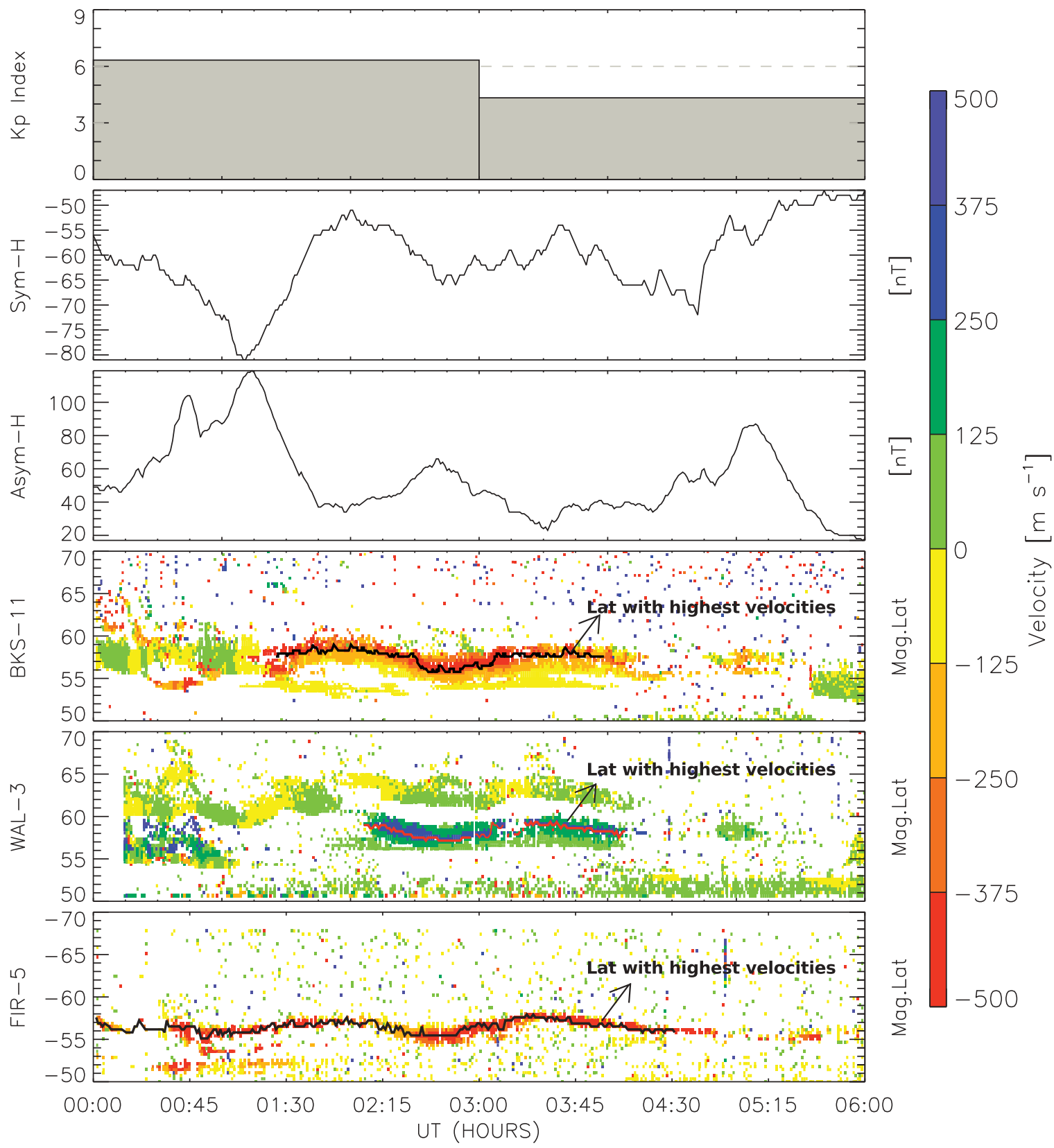

Figure 10. Time variations of data on August 4, 2010 from 00:00 UT to 06:00 UT. (top to bottom) Kp Index, Sym-H index, Asym-H index, radar $V_{L O S}$ observed by BKS (beam-11, magnetic azimuth: $-18.5^{\circ}$ ), WAL (beam-3, magnetic azimuth: $8.3^{\circ}$ ) and FIR (beam-5, magnetic azimuth: $-6.3^{\circ}$ ) radars versus magnetic latitude. The black line in the BKS beam-11 ( $\left.V_{L O S}\right)$ plot, the red line in the WAL beam-3 plot and the black line in the FIR beam-5 plot indicate the latitudes where the $V_{L O S}$ were highest.

in the Northern hemisphere and the FIR radar in the Southern hemisphere were reported. A correlation analysis (Table 1) revealed that the solar-wind and geomagnetic conditions had considerable influence on the channel morphology in both hemispheres. In this section we discuss these observations in more detail and compare them with results from previous studies.

[34] As mentioned in the previous section Lat ${ }_{\text {MAX }}$ in each radar exhibits a dependence on Asym-H index. The results from correlation analysis also show that Lat ${ }_{\text {MAX }}$ variations in the SAPS channel in both the hemispheres exhibit a good correlation between the hemispheres and with the Asym- $\mathrm{H}$ index. Moreover if the Lat MAx $_{\text {variations are passed through }}$ a moving-average filter they exhibit a significant improvement in the correlation coefficient. These results are in agreement with previous studies [Grocott et al., 2011; Erickson et al., 2011; Huang and Foster, 2007] and can be attributed to the dependence of the latitudinal position of the SAPS channel on the location of the ring current (the strength of the ring current is indicative of its location, the stronger the ring current the more closer it is to the Earth). Lat $_{\text {MAX }}$ in each radar also shows a good correlation with 

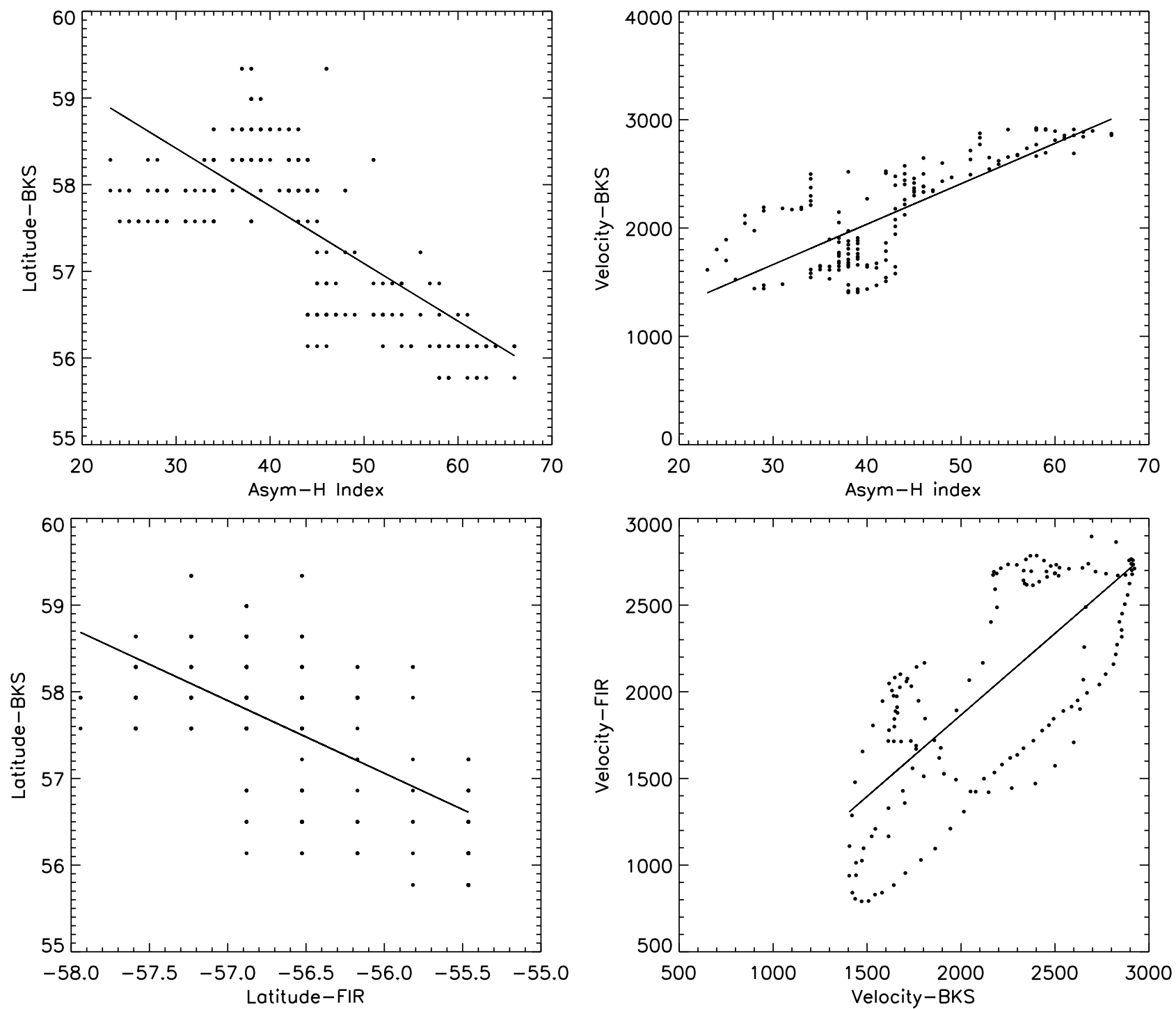

Figure 11. Scatter plots of (top left) BKS Lat velocity vs Asym-H index, (bottom right) FIR estimated zonal velocity vs BKS estimated zonal velocity, (bottom left) FIR Lat ${ }_{\text {MAX }}$ vs BKS Lat MAX.

IMF- $\mathrm{B}_{Z}$ which can be attributed to the dependence of the ring current on IMF-B $\mathrm{B}_{Z}$. As shown in Figure 9, $\mathrm{B}_{Z}$ during the interval of observations exhibits frequent northward and southward turnings. A southward directed IMF results in the intensification and earthward movement of the ring current thereby causing the SAPS channel in the ionosphere to move equatorward; when the IMF is northward directed, the SAPS channel moves poleward due to the weakening of the ring current. Similar dependence of the latitudinal position of SAPS on IMF-Bz has been reported in a statistical study by Erickson et al. [2011].

[35] We now calculate and estimate some other features of the channel. Figure 12 presents the variations in estimated zonal velocities in the SAPS channel (where the $V_{L O S}$ were highest), Pedersen current densities, latitudinal widths of the channel and the cross-SAPS potentials in both hemispheres vs time. The Pedersen current densities (second panel) are determined using the relation $\mathbf{J}_{\mathbf{P}}=\Sigma_{P} \mathbf{E}$. Here $\mathbf{J}_{\mathbf{P}}$ is the Pedersen current density, $\mathbf{E}$ is the electric field across the
Table 1. Results of Correlation Analysis ${ }^{\mathrm{a}}$

\begin{tabular}{|c|c|c|}
\hline Parameter-1 & Parameter-2 & Correlation Coefficient \\
\hline $\mathrm{FIR}_{\text {lat }}$ & IMF-B $_{Z}$ & -0.53 \\
\hline $\mathrm{BKS}_{\text {lat }}$ & IMF-B B & 0.56 \\
\hline $\mathrm{FIR}_{\text {lat }}$ & Asym-H & -0.58 \\
\hline $\mathrm{BKS}_{\text {lat }}$ & Asym-H & 0.65 \\
\hline $\mathrm{WAL}_{\text {lat }}$ & Asym-H & 0.69 \\
\hline $\mathrm{FIR}_{v e l}$ & Asym-H & 0.54 \\
\hline $\mathrm{BKS}_{v e l}$ & Asym-H & 0.57 \\
\hline $\mathrm{WAL}_{\text {lat }}$ & $\mathrm{FIR}_{\text {lat }}$ & -0.79 \\
\hline $\mathrm{BKS}_{\text {lat }}$ & $\mathrm{FIR}_{\text {lat }}$ & -0.73 \\
\hline $\mathrm{BKS}_{v e l}$ & $\mathrm{FIR}_{v e l}$ & 0.62 \\
\hline $\mathrm{BKS}_{P O T}$ & $\mathrm{FIR}_{P O T}$ & 0.81 \\
\hline
\end{tabular}

${ }^{\mathrm{a}} \mathrm{FIR}_{\text {lat }}, \mathrm{BKS}_{\text {lat }}$ and $\mathrm{WAL}_{\text {lat }}$ refer to the latitudes at which $V_{L O S}$ were highest (explained in section 3.3, Figure 10). $\mathrm{BKS}_{v e l}$ and $\mathrm{FIR}_{v e l}$ refer to the estimated zonal velocities in the channel where $V_{L O S}$ were highest (explained in section 3.2, Figure 12). $\mathrm{BKS}_{P O T}$ and $\mathrm{FIR}_{P O T}$ refer to the cross-SAPS potentials estimated in BKS and FIR radars (explained in section 4, Figure 12). 

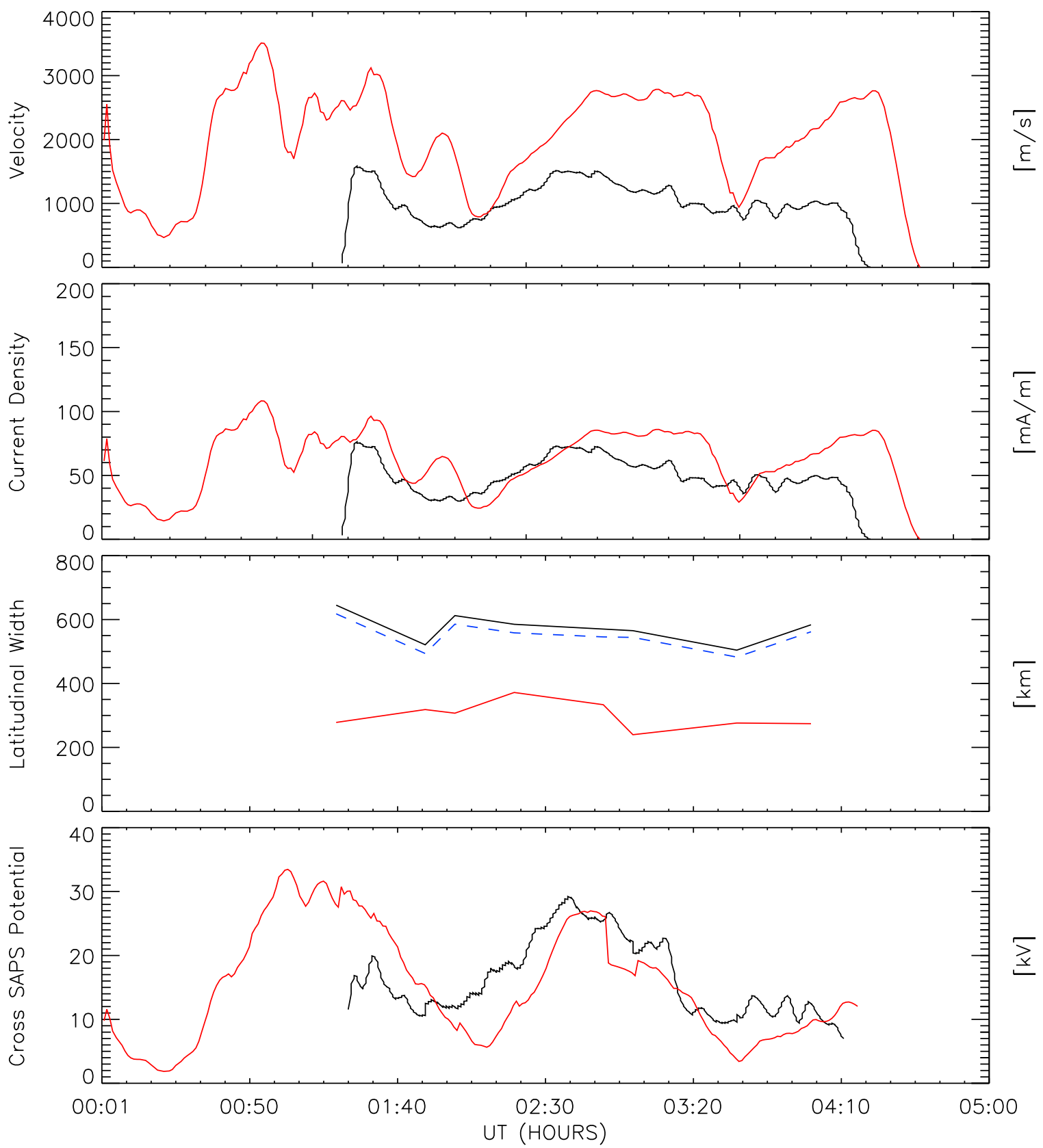

Figure 12. Time series data. (top to bottom) Magnitudes of the estimated zonal velocities, current densities in the SAPS channel, latitudinal width of the SAPS channel and the Potentials across the SAPS channel, observed by the BKS radar (solid black line) and the FIR radar (solid red line). The dotted blue line in the third panel represents the projection of the latitudinal width of the channel in the Northern hemisphere along the magnetic field lines into the Southern hemisphere using the Tsyganenko T01 model.

channel and $\Sigma_{P}$ is the height integrated Pedersen conductivity. The electric field across the channel is calculated assuming $\mathbf{E} \times \mathbf{B}$ drift. The magnitude of the Earth's magnetic field near the SAPS scatter region in the Northern hemisphere was estimated to be $56000 \mathrm{nT}$ and $48200 \mathrm{nT}$ in the Southern hemisphere using the IGRF-11 [Finlay et al., 2010] coefficients. The relatively large difference between the field strengths in the Northern and Southern hemispheres is because of the proximity of the FIR radar to the south Atlantic anomaly (SAA). The value of height integrated Pedersen conductivity due to electron precipitation was calculated using the empirical formula from Robinson et al. [1987], given below.

$$
\Sigma_{P}=\frac{40 E_{a v g} \phi_{E}^{1 / 2}}{16+E_{a v g}^{2}} .
$$

[36] Here $E_{\text {avg }}$ is the average energy of the precipitating electrons in $\mathrm{KeV}$ and $\phi_{E}$ is the electron energy flux in ergs/ $\mathrm{cm}^{2} \mathrm{~s}$. The values of $E_{a v g}$ and $\phi_{E}$ can be computed from the electron flux data of the SSJ/4 instrument [Hardy, 1984] 
aboard the DMSP F18 spacecraft. The height integrated Pedersen conductivity was found to be 0.65 mhos in the Northern hemisphere at 01:50 UT and 0.54 mhos in the Southern hemisphere at 01:15 UT. An average background Pedersen conductivity of 0.21 mhos in the Northern hemisphere and 0.09 mhos in the Southern hemisphere was added to the conductivity due to electron precipitation. The background conductivity values were estimated using the IRI-2007 model ionosphere [Bilitza and Reinisch, 2008]. The heightintegrated Pedersen conductivity was assumed to be constant throughout the event due to the lack of high time resolution measurements. This might miss any finer variations but will provide us with a overview of the inter-hemispheric differences in Pedersen currents.

[37] The cross-SAPS potential $\left(V_{S A P S}\right)$ shown in the bottom panel, denotes the potential difference across the SAPS channel. It has been estimated using the relation between potential difference and the electric fields given by $V_{S A P S}=\int_{X_{E}}^{X_{P}} E \mathrm{~d} x$. Here $\mathrm{d} x$ represents the latitudinal width of the SAPS channel and $X_{E}, X_{P}$ represent the equatorward and poleward edges of the SAPS channel respectively. It is seen that the SAPS potentials track one another to the first order and that the SAPS potentials can reach several tens of $\mathrm{kv}$.

[38] The variations in estimated zonal velocities (at the location where $V_{L O S}$ were maximum) observed in the BKS and FIR radars are presented in the top panel of Figure 12. It can be noted from the figure that the velocities are in general higher in the Southern hemisphere and they differ not only in magnitudes, but also in their temporal variations. The results from correlation analysis also show that the velocities exhibit moderate correlation between the hemispheres and with the Asym-H index. These inter-hemispheric differences suggest that although the velocities in the SAPS channel are influenced by the strength of the asymmetric ring current, there are other local factors such as the height integrated Pedersen conductivity which have a strong influence on the electric fields in the ionosphere. Some inter-hemispheric differences in the magnitude of the flows (up to $15 \%$ ) can be expected because of the SAA. However, the differences observed here are much stronger (reaching up to $90 \%$ ) than those expected due to the anomaly.

[39] From the second panel of Figure 12 it can be observed that the estimated Pedersen current densities are generally higher in the Southern hemisphere compared to the Northern hemisphere. This is consistent with results presented in previous studies such as [Ohtani et al., 2005; Fujii and Iijima, 1987] which demonstrated through statistical analyses that the Region-2 field aligned currents are more intense in the winter hemisphere (Southern hemisphere in this study) compared to the summer hemisphere on the nightside. The most likely causes for these differences were suggested to be asymmetric driving in the magnetosphere and the effects of seasonal differences in ionospheric conductivity [Ohtani et al., 2005; Fedder and Lyon, 1987; Ridley, 2007; Ridley et al., 2004].

[40] Another important feature of a SAPS channel is its latitudinal width (third panel of Figure 12). It can be observed from the figure that the latitudinal width of the channel is different in both the hemispheres. A similar inter-hemispheric difference in the separation between electron and ion precipitation boundaries and the observations made in DMSP ion drift meter were noted Section 3.1, which corroborates the difference observed by the radars. The boundaries of the SAPS channel in both hemispheres map along the magnetic field lines into the inner magnetosphere at $\sim 4 R_{E}$, where the Earth's magnetic field is generally expected to be very close to dipolar. A quasi-dipolar field suggests that the latitudinal width of the channel should be similar in both the hemispheres, unlike the observations presented here. Magnetic mapping of the SAPS channel showed that the Tsyganenko 'T96', 'T01' and 'T04S' models [Tsyganenko and Stern, 1996; Tsyganenko, 2002; Tsyganenko and Sitnov, 2005] do not predict the inter-hemispheric differences in latitudinal width observed here, for the geomagnetic conditions during the event. The results presented in Tsyganenko et al. [2003] and Tsyganenko and Sitnov [2005], showed that during severe geomagnetic storms (Dst index $\leq-250 \mathrm{nT}$ ) the quasidipolar approximation of the geomagnetic field breaks down at distances as small as $\sim 4-5 R_{E}$ and the field starts exhibiting a tail like deformation. However, during the event presented in the current paper the Dst index reached a peak value of $-65 \mathrm{nT}$. This suggests the possibility of a tail like distortion in the Earth's magnetic field at midlatitudes even during moderate geomagnetic storms.

[41] The final and most interesting feature of SAPS we examine is the potential across the channel, presented in the last panel of Figure 12. Unlike the other features, the crossSAPS potentials exhibited a lot of similarity in both magnitudes and temporal variations between the hemispheres. The high-degree of similarity in cross-SAPS potentials estimated in both hemispheres was further verified by a strong correlation coefficient of 0.81 between $\mathrm{BKS}_{P O T}$ and $\mathrm{FIR}_{P O T}$ (Table 1). It is important to note here that the latitudinal width has a significant influence on the cross-SAPS potentials. The electric fields were in general higher in the Southern hemisphere, whereas the latitudinal width of the channel was greater in the Northern hemisphere. These influences seem to counterbalance each other, reconciling the differences in velocity and latitudinal width with similar cross-SAPS potentials in the two hemispheres. This suggests that in spite of the presence of asymmetries between the hemispheres, there is overall consistency in terms of the conjugate mapping of potential variations between the hemispheres. The similar potential differences across the Northern and Southern hemisphere channels likely implies the absence of any fieldaligned potential drops.

\section{Conclusions}

[42] In this paper simultaneous observations of latitudinally narrow high velocity flow channels made by SuperDARN radars in both hemispheres with magnetically conjugate fields-of-view were presented. Examination of the geomagnetic conditions and the features of the channel such as its subauroral location indicated that these were SAPS channels. The line-of-sight velocities observed by the radars were seen to exhibit a nearly sinusoidal dependence on the magnetic azimuth. A sine curve fitting showed that the direction of flow was nearly westward in both the hemispheres. A correlation analysis revealed that the latitudinal location of the SAPS channel in both hemispheres was related to the strength of the asymmetric ring current, showing that the location of 
SAPS channel is influenced by the asymmetric ring current. However, the variations in the velocity of the channel exhibited a moderate correlation with the Asym-H index indicating that local ionospheric conditions such as the height integrated Pedersen conductivity have an important influence on the channel.

[43] An inter-hemispheric comparison of electric fields, Pedersen currents and cross-SAPS potentials showed that the Pedersen currents and electric fields exhibited substantial differences between the hemispheres. This can be attributed to seasonal differences in ionospheric conductivity between hemispheres, inner magnetospheric magnetic distortion or asymmetric driving of field-aligned currents in the magnetosphere. However, it was seen that the cross-SAPS potentials in both the hemispheres were similar not only in magnitudes but also in temporal variations. The greater consistency in terms of cross-SAPS potentials was due to compensating differences in SAPS velocities and channel widths between the hemispheres. Thus we can conclude that the SAPS phenomenon is consistent with conjugacy in terms of potential variations while exhibiting significant differences in latitudinal extent and convection velocities.

[44] Acknowledgments. The authors thank the National Science Foundation for support under grants ATM-0849031, ATM-0946900 and AGS-1150789. The Blackstone SuperDARN radar was built with funds provided by NSF and with contributions from University of Leicester (UK) and Virginia Tech. The Falkland Islands SuperDARN radar was supported by the UK Natural Environment Research Council grants NE/G019665/1 and NE/G018707/1. The DMSP particle detectors were designed by Dave Hardy of AFRL and data obtained from JHU/APL. DMSP SSIES ion drift meter data is collected by the US Airforce weather agency and processed by NOAA's National Geophysical Data Center. Kp, Sym-H and Asym-H indices were obtained from the World Data Center in Kyoto. The OMNI data were obtained from the GSFC/SPDF OMNIWeb interface at http://omniweb. gsfc.nasa.gov.

[45] Robert Lysak thanks the reviewers for their assistance in evaluating this paper.

\section{References}

Anderson, P., R. Heelis, and W. Hanson (1991), The ionospheric signatures of rapid subauroral ion drifts, J. Geophys. Res., 96(A4), 5785-5792.

Anderson, P. W. Hanson, R. Heelis, J. Craven, D. Baker, and L. Frank (1993), A proposed production model of rapid subauroral ion drifts and their relationship to substorm evolution, J. Geophys. Res., 98(A4), 6069-6078.

Anderson, P., D. Carpenter, K. Tsuruda, T. Mukai, and F. Rich (2001), Multisatellite observations of rapid subauroral ion drifts (SAID), J. Geophys. Res., 106, 29,585-29,599.

Bilitza, D., and B. Reinisch (2008), International reference ionosphere 2007: Improvements and new parameters, Adv. Space Res., 42(4), 599-609.

Clausen, L., et al. (2012), Large-scale observations of a subauroral polarization stream by midlatitude SuperDARN radars: Instantaneous longitudinal velocity variations, J. Geophys. Res., 117, A05306, doi:10.1029/ 2011JA017232

Erickson, P., F. Beroz, and M. Miskin (2011), Statistical characterization of the American sector subauroral polarization stream using incoherent scatter radar, J. Geophys. Res., 116, A00J21, doi:10.1029/2010JA015738.

Fedder, J., and J. Lyon (1987), The solar wind-magnetosphere-ionosphere current-voltage relationship, Geophys. Res. Lett., 14(8), 880-883.

Feldsten, Y., and G. Starkov (1967), Dynamics of auroral belt and polar geomagnetic disturbances, Planet. Space Sci., 15(2), 209-229.

Fillingim, M., G. Parks, H. Frey, T. Immel, and S. Mende (2005), Hemispheric asymmetry of the afternoon electron aurora, Geophys. Res. Lett., 32, L03113, doi:10.1029/2004GL021635.

Finlay, C., et al. (2010), International geomagnetic reference field: The eleventh generation, Geophys. J. Int., 183, 1216-1230.

Foster, J. (1995), Radar observations of magnetosphere-ionosphere coupling at mid and high latitudes, J. Geomagn. Geoelectr., 47(8), 801-812.

Foster, J., and W. Burke (2002), SAPS: A new characterization for subauroral electric fields, Eos Trans. AGU, 83(36), 393.
Foster, J., and F. Rich (1998), Prompt midlatitude electric field effects during severe geomagnetic storms, J. Geophys. Res., 103, 26,367-26,372.

Foster, J., and W. Rideout (2007), Storm enhanced density: Magnetic conjugacy effects, Ann. Geophys. 25, 1791-1799.

Foster, J., and H. Vo (2002), Average characteristics and activity dependence of the subauroral polarization stream, J. Geophys. Res., 107(A12), 1475, doi:10.1029/2002JA009409.

Frank, L., and J. Sigwarth (2003), Simultaneous images of the northern and southern auroras from the polar spacecraft: An auroral substorm, J. Geophys. Res., 108(A4), 8015, doi:10.1029/2002JA009356.

Freeman, M., J. Ruohoniemi, and R. Greenwald (1991), The determination of time-stationary two-dimensional convection patterns with singlestation radars, J. Geophys. Res., 96(A9), 15,735-15,749.

Freeman, M., D. Southwood, M. Lester, T. Yeoman, and G. Reeves (1992), Substorm-associated radar auroral surges, J. Geophys. Res., 97(A8), $12,173-12,185$.

Fujii, R., and T. Iijima (1987), Control of the ionospheric conductivities on large-scale birkeland current intensities under geomagnetic quiet conditions, J. Geophys. Res., 92(A5), 4505-4513.

Galperin, Y., V. Ponomarev, and A. Zosimova (1974), Direct Measurements of Ion Drift Velocity in the Upper Ionosphere During a Magnetic Storm. Part 2: Results of Measurements During the November 3, 1967 Magnetic Storm, Inst. for Space Res., Moscow.

Grocott, A., S. Milan, J. Baker, M. Freeman, M. Lester, and T. Yeoman (2011), Dynamic sub-auroral ionospheric electric fields observed by the falkland islands radar during the course of a geomagnetic storm, J. Geophys. Res., 116, A11202, doi:10.1029/2011JA016763.

Gussenhoven, M., D. Hardy, and W. Burke (1981), DMSP/F2 electron observations of equatorward auroral boundaries and their relationship to magnetospheric electric fields, J. Geophys. Res., 86(A2), 768-778.

Hardy, D. (1984), Precipitating electron and ion detectors (SSJ/4) for the block 5D/flights 6-10 DMSP (defense meteorological satellite program) satellites: Calibration and data presentation, Tech. Rep. AFGL-TR-840317, Air Force Geophys. Lab., Hanacom AFB, Mass.

Heinemann, N., M. Gussenhoven, D. Hardy, F. Rich, and H. Yeh (1989), Electron/ion precipitation differences in relation to region 2 field-aligned currents, J. Geophys. Res., 94(A10), 13,593-13,600.

Huang, C., and J. Foster (2007), Correlation of the subauroral polarization streams (SAPS) with the Dst index during severe magnetic storms, J. Geophys. Res., 112, A11302, doi:10.1029/2007JA012584.

Iyemori, T. (1990), Storm-time magnetospheric currents inferred from midlatitude geomagnetic field variations, J. Geomagn. Geoelectr., 42(11), $1249-1265$.

Karlsson, T., G. Marklund, and L. Blomberg (1998), Subauroral electric fields observed by the freja satellite: A statistical study, J. Geophys. Res., 103(A3), 4327-4341.

King, J., and N. Papitashvili (2005), Solar wind spatial scales in and comparisons of hourly wind and ace plasma and magnetic field data, J. Geophys. Res., 110, A02104, doi:10.1029/2004JA010649.

Koustov, A., R. Drayton, R. Makarevich, K. McWilliams, J. St-Maurice, T. Kikuchi, and H. Frey (2006), Observations of high-velocity SAPS-like flows with the King Salmon SuperDARN radar, in Ann. Geophys., 24, $1591-1608$.

Maeda, H. (1974), Field-aligned current induced by asymmetric dynamo action in the ionosphere, J. Atmos. Terr. Phys., 36(8), 1395-1401.

Makarevich, R., and P. Dyson (2008), Dual HF radar study of the subauroral polarization stream, Ann. Geophys., 25, 2579-2591.

Ohtani, S., G. Ueno, T. Higuchi, and H. Kawano (2005), Annual and semiannual variations of the location and intensity of large-scale field-aligned currents, J. Geophys. Res., 110, A01216, doi:10.1029/2004JA010634.

Oksavik, K., R. Greenwald, J. Ruohoniemi, M. Hairston, L. Paxton, J. Baker, J. Gjerloev, and R. Barnes (2006), First observations of the temporal/spatial variation of the sub-auroral polarization stream from the superdarn wallops HF radar, Geophys. Res. Lett., 33, L12104, doi:10.1029/2006GL026256.

Østgaard, N., S. Mende, H. Frey, T. Immel, L. Frank, J. Sigwarth, and T. Stubbs (2004), Interplanetary magnetic field control of the location of substorm onset and auroral features in the conjugate hemispheres, J. Geophys. Res., 109, A07204, doi:10.1029/2003JA010370.

Parkinson, M., M. Pinnock, H. Ye, M. Hairston, J. Devlin, P. Dyson, R. Morris, and P. Ponomarenko (2003), On the lifetime and extent of an auroral westward flow channel (awfc) observed during a magnetospheric substorm, Ann. Geophys., 21, 893-913.

Parkinson, M., M. Pinnock, J. Wild, M. Lester, T. Yeoman, S. Milan, H. Ye, J. Devlin, H. Frey, and T. Kikuchi (2005), Interhemispheric asymmetries in the occurrence of magnetically conjugate sub-auroral polarisation streams, Ann. Geophys., 23, 1371-1390.

Parkinson, M., J. Wild, C. Waters, M. Lester, E. Lucek, and P. Décréau (2007), An auroral westward flow channel (AWFC) and its relationship 
to field-aligned current, ring current, and plasmapause location determined using multiple spacecraft observations, Ann. Geophys., 25, 59-76.

Rich, F. J., and M. Hairston (1994), Large-scale convection patterns observed by DMSP, J. Geophys. Res., 99, 3827-3844.

Ridley, A. (2007), Effects of seasonal changes in the ionospheric conductances on magnetospheric field-aligned currents, Geophys. Res. Lett., 34, L05101, doi:10.1029/2006GL028444.

Ridley, A., T. Gombosi, and D. DeZeeuw (2004), Ionospheric control of the magnetosphere: Conductance, Ann. Geophys., 22, 567-584.

Robinson, R., R. Vondrak, K. Miller, T. Dabbs, and D. Hardy (1987), On calculating ionospheric conductances from the flux and energy of precipitating electrons, J. Geophys. Res., 92(A3), 2565-2569.

Ruohoniemi, J., R. Greenwald, K. Baker, J. Villain, and M. McCready (1987), Drift motions of small-scale irregularities in the high-latitude F region: An experimental comparison with plasma drift motions, J. Geophys. Res., 92(A5), 4553-4564.

Sato, N., and T. Saemundson (1987), Conjugacy of electron auroras observed by all-sky cameras and scanning photometers, Mem. Natl. Inst Polar Res., Spec. Issue, 48, 58-71.
Spiro, R., R. Heelis, and W. Hanson (1979), Rapid subauroral ion drifts observed by Atmosphere Explorer C, Geophys. Res. Lett., 6(8), 657-660. Stening, R. (1977), Field-aligned currents driven by the ionospheric dynamo, J. Atmos. Terr. Phys., 39(8), 933-937.

Sugiura, M. (1964), Hourly values of equatorial Dst for the igy, Ann. Int Geophys. Yr., 35, 7-45.

Tsyganenko, N. (2002), A model of the near magnetosphere with a dawndusk asymmetry 1. Mathematical structure, J. Geophys. Res., 107(A8), 1179, doi:10.1029/2001JA000219.

Tsyganenko, N., and M. Sitnov (2005), Modeling the dynamics of the inner magnetosphere during strong geomagnetic storms, J. Geophys. Res., 110, A03208, doi:10.1029/2004JA010798.

Tsyganenko, N., and D. Stern (1996), Modeling the global magnetic field of the large-scale Birkeland current systems, J. Geophys. Res., 101(A12), 27,187-27,198

Tsyganenko, N., H. Singer, and J. Kasper (2003), Storm-time distortion of the inner magnetosphere: How severe can it get, J. Geophys. Res., 108(A5), 1209, doi:10.1029/2002JA009808. 